Research report

\title{
Risk factors for Panic Disorder in pregnancy: A cohort study
}

\author{
Carlo Marchesi ${ }^{\mathrm{a}, \mathrm{b}, *}$, Paolo Ampollini ${ }^{\mathrm{b}}$, Cecilia Paraggio ${ }^{\mathrm{a}}$, Giovanna Giaracuni ${ }^{\mathrm{a}}$, \\ Paolo Ossola ${ }^{\mathrm{a}}$, Chiara De Panfilis ${ }^{\mathrm{a}, \mathrm{b}}$, Matteo Tonna ${ }^{\mathrm{b}}$, Daniela Viviani ${ }^{\mathrm{c}}$ \\ a Department of Neurosciences, Psychiatric Unit, University of Parma, Parma, Italy \\ ${ }^{\mathrm{b}}$ Department of Mental Health, Local Health Service, Parma, Italy \\ ${ }^{\mathrm{c}}$ Department of Obstetric and Gynecology, University Hospital, Parma, Italy
}

\section{A R T I C L E I N F O}

\section{Article history:}

Received 4 September 2013

Received in revised form

4 December 2013

Accepted 5 December 2013

Available online 17 December 2013

\section{Keywords:}

Panic Disorder

Major depression

Minor depression

Comorbidity

Risk factors

Pregnancy

\begin{abstract}
A B S T R A C T
Background: The study investigates the prevalence of Panic Disorder (PD) with or without comorbid Major (MD) or Minor Depressive (md) disorder during pregnancy and focuses its attention on the different pattern of risk factors in these two subgroups in a sample of women attending two Centres for Prenatal Care of the Public Health Service.

Methods: Two-hundred and seventy-seven pregnant women were assessed monthly throughout the whole pregnancy period using the Primary Care Evaluation of Mental Disorders (PRIME-MD) for the screening of PD and the Hospital Anxiety and Depression Scale (HADS) for the evaluation of severity of anxious and depressive symptoms.

Results: Twenty-one women (7.5\%) were diagnosed as affected by PD, of whom 12 (57.1\%) showed MD or md comorbidity. The development of PD without depressive comorbidity is predicted by a history of previous episodes of Anxiety Disorders while the development of PD plus depressive comorbidity is predicted by a history of previous depressive episodes and by the lack of familiar support.

Limitations: Given the small sample size of our anxious and depressed women, the present data need to be verified by using larger samples.

Conclusions: The frequent association between PD and MD or md, the analysis of risk factors and of temporal relationship strongly suggests that the panic-depressive comorbidity might represent in fact depressive disorders with intense anxiety symptoms. These findings raise the question if the PD-depressive association is a true comorbidity or reveals the anxious symptomatology of a depressive disorder (MD or $\mathrm{md})$.
\end{abstract}

(c) 2014 Elsevier B.V. All rights reserved.

\section{Introduction}

There is a consistent body of clinical research focusing on depression during the perinatal period, pregnancy and the first year postpartum, whereas anxiety disorders in these same periods have received less research attention. It was previously thought that pregnancy was a time of low risk for the new onset or exacerbation of an anxiety disorder. However, there is growing realization that symptoms of anxiety are common during pregnancy and postpartum and maternal symptoms of anxiety during pregnancy are associated with adverse fetal and developmental consequences.

Panic Disorder (PD) is one of the most prevalent and disabling anxiety disorders. According to the Epidemiological Catchment's Area population survey (Regier et al., 1990), lifetime prevalence for

\footnotetext{
* Correspondence to: University of Parma, Department of Neuroscience, Psychiatry Unit, University Hospital, Braga Building, 43126 Parma, Italy. Tel.: + 390521 903597; fax: + 390521396825 .

E-mail address: carlo.marchesi@unipr.it (C. Marchesi).
}

PD is estimated at $2.2 \%$, and women are $2.5-3$ times more likely than men to meet criteria for PD ( $3.4 \%$ vs. $0.9 \%$ ). The Epidemiological Catchment's Area data also demonstrated an increased risk for PD in those under age 45 years (Regier et al., 1990). International reports confirm that women have significantly higher prevalence rates of PD (Kessler et al., 1994; Alonso et al., 2004).

It has been estimated that $3-12 \%$ of women experience symptoms related to PD at some time during their childbearing years, including pregnancy and the postpartum period (Wenzel et al., 2001; Smith et al., 2004; Andersson et al., 2006; Goodman and Tyer-Viola, 2010), and according to available data 3-11\% of women with PD report the onset during perinatal period (Ross and McLean, 2006). PD is not only common but is also considered to be a chronic and debilitating illness associated with significant comorbidity (Ballenger et al., 1998; Yonkers et al., 1998). Noteworthy, approximately $50 \%$ of individuals with PD also have comorbid Major Depression (MD). Furthermore, several prospective studies have shown that a prenatal anxiety disorder is one of the strongest risk factors for developing postnatal depression (Andersson et al., 2003; Sutter-Dallay et al., 2004; Milgrom et al., 2008). Therefore, an 
anxiety disorder in pregnancy may be associated with significant maternal depressive morbidity.

Despite these important clues, there is lack of literature reporting risk factors for or predictors of antenatal PD and patterns of depressive comorbidity.

Therefore, the present study was aimed to investigate the prevalence of PD with or without comorbid depression at several times during pregnancy and to evaluate the pattern of risk factors in these two subgroups in a Italian sample of women attending two Centres for Prenatal Care of the Public Health Service.

\section{Methods}

Both the Local Ethical Committee (Comitato Unico della Provincia di Mantova e della Provincia di Reggio Emilia) approved the study protocol.

\subsection{Sample}

The study population was recruited among women who consecutively sought assistance at the Centres for Prenatal Care of the Public Health Service of District of Mantova (Italy) and Reggio Emilia (Italy), from September 2005.

Women participated in the study after the procedure had been fully explained and a written informed consent was obtained, if they were older than 18 years and completed all the evaluations from the beginning of their pregnancy.

\subsection{Assessment}

At each visit, all women were asked to complete (approximately every month) the following evaluations: (1) the Italian translation of the Primary Care Evaluation of Mental Disorders (PRIME-MD) (Spitzer et al., 1994) for the screening of PD; (2) the Italian translation of the Hospital Anxiety and Depression Scale (HADS) (Zigmond and Snaith, 1983) for the evaluation of severity of anxious and depressive symptoms.

Moreover, all women completed a brief questionnaire, performed ad hoc, to collect socio-demographic and medical history information, and to evaluate the presence (or absence) of problems with husband/partner, family, job, family support and whether the pregnancy was unwanted. The results of the questionnaire were discussed with the women (and when available with family members) to confirm their answers.

The PRIME-D is a structured interview for the diagnosis of mental disorders according to the criteria of DSM-IV (American Psychiatric Association, 1994). It has not been validated for the use in a pregnant population, however it showed good specificity and sensitivity in detecting PD (specificity 99\%, sensitivity 57\%) and MD (specificity $98 \%$, sensitivity $57 \%$ ) in primary care populations (Spitzer et al., 1994).

The interview was administered at each visit by the gynecologists, who were trained by a senior psychiatrist.

A woman was affected by PD if, at any evaluation during pregnancy, she fulfilled the criteria for a PD episode. A woman was defined non-anxious if she did not satisfy the criteria for PD or anxiety disorder not otherwise specified at any evaluation during pregnancy.

The duration and onset of PD (the month in which anxious symptoms firstly satisfied the diagnostic criteria for PD) throughout pregnancy were calculated. In women, who showed anxious symptoms at the first evaluation, the onset was arbitrarily considered the first month of pregnancy.

Concerning treatment of PD, only women with severe anxious symptoms (on clinical judgment) were referred by gynecologist to psychiatrist for a treatment. The gynecologists were properly trained to recognize this severe condition.

\subsection{Statistical analysis}

Comparisons between PD and non-anxious women were performed using the one-way analysis of variance with Bonferroni post-hoc analysis for continuous variables and with Fisher's exact test for categorical variables.

Stepwise logistic regression was used to evaluate which variables at the beginning of pregnancy could predict the development of depression. Two regression analysis were performed: the same independent variables entered in both analyses were occupation, number of childbirths, presence of problems with husband/partner, family, job, presence of family support and whether the pregnancy was unwanted, whereas the dependent variables were MD and no depression in one analysis and md and no depression in the other analysis.

\section{Results}

\subsection{Sample}

During the study period, 356 women attended the Centres of Prenatal Care. Thirty-two women $(8.9 \%)$ were not included in the study because of language problems $(n=17)$ or refusal to participate $(n=15)$. Among the remaining 324 women, $25(7.7 \%)$ were excluded from the study because they did not attend all the visits throughout pregnancy. Among non-completers, 15 dropped-out after the first evaluation, 7 attended another visit and 3 two more visits. At the beginning of pregnancy, the 25 non-completers showed the same socio-demographic features of the completers. Moreover, none of the non-completers showed anxious or depressive symptoms at any evaluation they attended.

Among the remaining 299 women, 22 women were excluded from the study because they presented during pregnancy anxious symptoms, which did not satisfy the diagnostic criteria of PD (anxiety disorder not otherwise specified). However, women with anxiety disorder not otherwise specified were considered when the prevalence of PD was calculated.

Therefore the study population included 277 women (mean age $30.7 \pm 4.4$ years; range $18-45$ years. Twenty-one women were diagnosed as affected by PD and the remaining 256 did not present anxious symptoms during pregnancy (healthy controls) (C). PD and $\mathrm{C}$ women showed the same age, years of education and family or occupational status, whereas PD women had higher number of childbirths, more frequently reported an absence of family support and depressive or anxious episode before pregnancy (Table 1). Moreover, PD and $\mathrm{C}$ women showed the same number of assessments ( $\mathrm{PD}=6.1 \pm 1.3$ vs. $\mathrm{C}=6.0 \pm 1.3 ; t=0.43 ; p=0.66)$.

In anxious women, the PD symptoms became evident after $4.0 \pm 2.1$ months of pregnancy and they lasted $3.0 \pm 2.0$ months (Table 2).

\subsection{Depressive comorbidity}

PD women showed more depressive episodes during pregnancy that C (Table 1). Twelve PD women (57.1\%) presented depressive episode during pregnancy: MD was diagnosed in 5 anxious women and $\mathrm{md}$ in 7 . In seven women, PD was concomitant with $\mathrm{MD}(n=3)$ or $\mathrm{md}(n=4)$ whereas in 5 women PD preceded $\mathrm{MD}(n=2)$ or $\mathrm{md}(n=3)$.

Concerning treatments, no anxious or depressed women were treated with antidepressants or other psychotropic drugs. Only two women with MD received a psychological support. 
Table 1

Socio-demographic and clinical features in women who developed major depression or. minor depression during pregnancy and in healthy pregnant women

\begin{tabular}{|c|c|c|c|c|c|}
\hline & & $\begin{array}{l}\text { Panic } \\
\text { Disorder } \\
(n=21)\end{array}$ & $\begin{array}{l}\text { No anxiety } \\
(n=256)\end{array}$ & & \\
\hline Age (years) & & $31.9 \pm 3.9$ & $30.7 \pm 4.4$ & $t=1.2$ & $p=0.23$ \\
\hline Education (years) & & $11.0 \pm 3.1$ & $12.3 \pm 3.3$ & $t=1.7$ & $p=0.08$ \\
\hline $\begin{array}{l}\text { Family status } \\
\text { Never married } \\
\text { Married } \\
\text { Living together } \\
\text { Separated/Divorced }\end{array}$ & & $\begin{array}{l}2(9.5 \%) \\
18(85.7 \%) \\
1(4.8 \%) \\
-\end{array}$ & $\begin{array}{l}41(16.0 \%) \\
186(72.7 \%) \\
27(10.5 \%) \\
2(0.8 \%)\end{array}$ & $\chi^{2}=4.7$ & $p=0.58$ \\
\hline $\begin{array}{l}\text { Occupation } \\
\text { Unemployed } \\
\text { Student } \\
\text { Housewife } \\
\text { Employed }\end{array}$ & & $\begin{array}{l}0 \\
0 \\
6(37.5 \%) \\
10(62.5 \%)\end{array}$ & $\begin{array}{l}1(0.8 \%) \\
2(1.7 \%) \\
8(7.1 \%) \\
101(90.1 \%)\end{array}$ & $\chi^{2}=4.3$ & $p=0.21$ \\
\hline $\begin{array}{l}\text { Depression during } \\
\text { pregnancy } \\
\text { No depression } \\
\text { Major depression } \\
\text { Minor depression }\end{array}$ & & $\begin{array}{l}9(42.8 \%) \\
5(23.8 \%) \\
7(33.3 \%)\end{array}$ & $\begin{array}{l}214(83.6 \%) \\
13(5.1 \%) \\
29(11.3 \%)\end{array}$ & $\chi^{2}=18.1$ & $p=0.001$ \\
\hline $\begin{array}{l}\text { Number of children } \\
\text { Problems with } \\
\text { husband/partner }\end{array}$ & Yes & $\begin{array}{l}0.90 \pm 0.83 \\
1(4.8 \%)\end{array}$ & $\begin{array}{l}0.54 \pm 0.63 \\
6(2.3 \%)\end{array}$ & $\begin{array}{l}t=2.4 \\
\chi^{2}=0.4\end{array}$ & $\begin{array}{l}p=0.01 \\
p=0.42\end{array}$ \\
\hline $\begin{array}{l}\text { Problems with } \\
\text { family }\end{array}$ & Yes & $2(9.5 \%)$ & $5(2.0 \%)$ & $\chi^{2}=4.5$ & $p=0.09$ \\
\hline Problems with job & Yes & $3(14.3 \%)$ & $29(11.3 \%)$ & $\chi^{2}=0.1$ & $p=0.72$ \\
\hline Family support & No & $11(52.4 \%)$ & $60(23.4 \%)$ & $\chi^{2}=8.5$ & $p=0.006$ \\
\hline $\begin{array}{l}\text { Unwanted } \\
\text { pregnancy }\end{array}$ & Yes & $5(23.8 \%)$ & $83(32.4 \%)$ & $\chi^{2}=0.6$ & $p=0.47$ \\
\hline $\begin{array}{l}\text { Previous anxiety } \\
\text { episodes }\end{array}$ & Yes & $14(66.7 \%)$ & $46(18.0 \%)$ & $\chi^{2}=27.1$ & $p<0.001$ \\
\hline $\begin{array}{l}\text { Previous depressive } \\
\text { episodes }\end{array}$ & Yes & $12(57.1 \%)$ & $31(12.1 \%)$ & $\chi^{2}=30.0$ & $p<0.001$ \\
\hline
\end{tabular}

\subsection{Predictive risk of developing $P D$}

At the beginning of pregnancy when PD women were compared with non-anxious women using the stepwise logistic regression, the risk factors for developing PD were different for PD without depression and for PD with depressive comorbidity.

The development of PD without depressive comorbidity was predicted by the presence of previous anxious episode $\left(\chi^{2}=11.4\right.$; $p=0.001 ; \mathrm{OR}=15.9 ; \mathrm{CI} 95 \%=3.2-79.4)$, whereas number of childbirths, unwanted pregnancy, conflict with the husband/partner, problems with the family or the job, family support and previous depressive episodes did not show any effect (Table 3 ).

The development of PD with depressive comorbidity was predicted by the presence of previous depressive episode $\left(\chi^{2}=14.1\right.$; $p<0.0011 ;$ OR $=10.1$; CI 95\%=3.0-33.9) and by the absence of family support $\left(\chi^{2}=4.7 ; \mathrm{p}=0.03 ; \mathrm{OR}=4.2\right.$; IC $\left.95 \%=1.1-15.5\right)$, whereas number of childbirths, unwanted pregnancy, conflict with the husband/partner, problems with the family or the job, and previous anxious episodes did not show any effect (Table 3).

\section{Discussion}

To our knowledge, this is the first prospective study investigating the presence of PD nearly at monthly intervals throughout pregnancy. The frequent assessment of PD $(6.1 \pm 1.3$ times) gave the possibility to evaluate the duration of the anxious episode and its relationship with MD or md. In our sample, 21 women (7.0\%) were diagnosed as affected by PD, of whom 12 showed MD or md comorbidity. It is difficult to compare our result to other studies
Table 2

Onset and duration of PD in women with or without depressive disorder (both MD and $\mathrm{md}$ )

\begin{tabular}{|c|c|c|c|c|}
\hline & \multicolumn{4}{|c|}{ Panic Disorder } \\
\hline & \multicolumn{2}{|c|}{ With $\mathrm{D}(n=12)$} & \multicolumn{2}{|c|}{ Without $\mathrm{D}(n=9)$} \\
\hline \multicolumn{5}{|l|}{ Onset } \\
\hline Trimester $1 \mathrm{st}$ & 4 & $33.3 \%$ & 4 & $44.4 \%$ \\
\hline Trimester 2nd & 7 & $58.3 \%$ & 1 & $11.1 \%$ \\
\hline Trimester 3rd & 1 & $8.3 \%$ & 4 & $44.4 \%$ \\
\hline Duration months & \multicolumn{2}{|c|}{$3.2 \pm 0.9$} & \multicolumn{2}{|c|}{$2.7 \pm 1.6$} \\
\hline
\end{tabular}

Onset $\chi^{2}=5.9 ; \mathrm{df}=1 ; p=0.05$

Duration $t=0.8 ; \mathrm{df}=19 ; p=0.42$.

Table 3

Risk factors for developing Panic Disorder (PD) with or without depression in pregnant women.

\begin{tabular}{|c|c|c|c|c|c|c|}
\hline Presence of PD in pregnant $\mathrm{w}$ & $\begin{array}{c}\text { ome } \\
\beta\end{array}$ & $\chi^{2}$ Wald & $\boldsymbol{p}$ & OR & CI 95\% & $R^{2}$ \\
\hline $\begin{array}{l}\text { PD without depression } \\
\text { Previous anxious episodes }\end{array}$ & 2.7 & 11.4 & 0.001 & 15.9 & $3.2-79.4$ & 0.21 \\
\hline $\begin{array}{l}\text { PD with depression } \\
\text { Step } 1 \\
\text { Previous depressive episodes }\end{array}$ & 2.3 & 14.1 & $<0.001$ & 10.1 & $3.0-33.9$ & 0.16 \\
\hline $\begin{array}{l}\text { Step } 2 \\
\text { Family support (no) } \\
\text { Previous depressive episodes }\end{array}$ & $\begin{array}{l}1.4 \\
1.9\end{array}$ & $\begin{array}{l}4.7 \\
9.1\end{array}$ & $\begin{array}{l}0.03 \\
0.002\end{array}$ & $\begin{array}{l}4.2 \\
6.9\end{array}$ & $\begin{array}{l}1.1-15.5 \\
1.9-24.6\end{array}$ & 0.22 \\
\hline
\end{tabular}

The independent variables entered in each logistic regression were: age, number of sons, unwanted pregnancy, family support, problems with husband/partner, problems with family, problems with job, previous anxious or depressive episodes.

focusing on the prevalence of PD during pregnancy because they are few and there are deep methodological differences between them (Ross and McLean, 2006; Guler et al., 2008). Previous studies focused on point prevalence at a specific period during pregnancy (2nd trimester, 3rd trimester), our research otherwise point at a prevalence throughout all the duration of pregnancy. Moreover there are methodological discrepancies concerning the diagnostic methodology (different self-report measures, clinical interviews) (Guler et al., 2008). However our prevalence rates is in line with the data from the literature which report that $3 \%$ to $12 \%$ of women experience symptoms related to PD at some time during their childbearing years, including pregnancy and the postpartum period (Wenzel et al., 2001; Smith et al., 2004; Andersson et al., 2006; Goodman and Tyer-Viola, 2010;), and according to available data, $3-11 \%$ of women with PD report the onset during perinatal period (Ross and McLean, 2006).

Concerning the socio-demographic characteristics, PD women compared with controls, showed lower level of education, higher number of childbirths and a lower family support. However, only the lack of family support represented a risk factor for developing PD during pregnancy in multivariate analysis (see below).

Moreover, PD women, compared to controls, showed significant higher rates of depressive comorbidity, both MD and md, and they had more frequently anxious or depressive episodes before pregnancy.

The high prevalence of depressive comorbidity (57\%) in pregnant women with PD confirms the data from the literature (Kaufman and Charney, 2000), which reports that MD occurs in patients with PD in 56-73\% of cases. We do not acknowledge previous studies exploring prevalence of PD-depression comorbidity during pregnancy.

While analyzing the rate of PD among the three trimester of pregnancy we found that women with pure PD showed the typical 
"U-shaped" pattern (Figueiredo and Conde, 2011), also observed in GAD population during pregnancy (Buist et al., 2011), with incidence decreasing from the 1 st to the 2 nd trimester and then increasing from the 2nd trimester with the proximity of childbirth. Women with PD and comorbid depression showed a "reverse U-shaped" pattern, with an increase of incidence from 1st to 2nd trimester and a dramatic fall of the incidence in the 3rd trimester. To our knowledge no studies reported the incidence of PD comorbid with mood disorders among the three trimester of pregnancy. Many authors who studied the timing of MD during pregnancy reported a decrease in depression from the 1st to the 3rd pregnancy trimester (Figueiredo and Conde, 2011).

Some authors (Figueiredo and Conde, 2011) suggest that the increase in anxiety symptoms from the 2nd to 3rd pregnancy trimester may be related with the proximity of childbirth and the decrease in depression symptoms from the 2nd to the 3rd pregnancy trimester with the emergent presence of the newborn in the parent's life. However, it might also be supposed that the U-shaped pattern of the frequency of PD during pregnancy reflect the effect of the stressor that exerts its highest effect in the beginning of its action (1st trimester) and in proximity to the end ( $3 r$ trimester) when the difficulties in the management of the new life event are higher. Otherwise, biological adjustments can also be related with these psychological changes.

In this study we found different patterns of risk factors when comparing women who developed PD during pregnancy with and without depressive disorder.

The development of PD without depressive comorbidity is predicted by a history of previous anxious episodes while the development of PD plus depressive comorbidity is predicted by a history of previous depressive episodes and by the lack of familiar support.

This finding is in line with previous worldwide researches stating that the most consistent risk factors of depressive disorder during pregnancy and post partum are a problematic familiar relationships and previous depressive episodes (Dietz et al., 2007; Marchesi et al., 2009; Lancaster et al., 2010), suggesting that pregnant women with comorbid PD and depression share the common risk factors of depressive states.

This finding raises the question if the pattern of PD-depressive comorbidity found in our study represents true comorbidity between two distinct disorders (PD and MD or md) or otherwise reveals the anxious symptomatology of a depressive disorder (MD or md). A closer look to the temporal relationship between PD and depressive disorders shows that in 11 of 12 gestants (91.7\%) the two comorbid entities coexist (synchronic or intra-episodic comorbidity) and in one sole case the two disorder appear temporally unrelated. Analyzing the data of intra-episodic comorbidity, in five pregnant women $(45.4 \%)$ the two disorders show a common onset, in four cases $(36.4 \%)$ the onset of PD precedes the onset of depressive disorder. Only in two cases (18.2\%) the onset of depression precedes the onset of PD. Taken together, the data of risk factors and of temporal relationship strongly suggests that maybe the panic-depressive comorbidity observed in this study represents in fact depressive disorders with intense anxiety symptoms. However, we cannot exclude that this comorbidity might be an artifact due to the limitations of the diagnostic instrument (the PRIME-MD interview) and its inability to detect true panic-depression comorbidity.

To our knowledge no studies explored the predictors of PD in perinatal period; one study found that Generalized Anxiety Disorder (GAD) during pregnancy is predicted by previous GAD episodes (Buist et al., 2011). These two findings taken together suggest that anxiety symptoms are predicted by previous anxious episodes.

This study confirms that PD is a common and troublesome condition during pregnancy and postpartum and may have severe consequences on mother mental health as well as depressive disorders. Moreover, in almost a half of the cases the two conditions may frequently coexist, in the mean time or at different intervals, in the same subjects. Our study raises the question that often panic, at least as measured by PRIME-MD, might be a prodromal or an anxious manifestation of a depressive disorder (MD or md). It is therefore strongly recommended an effort to screen and precociously intervent on these pathological conditions. A complete social and medical history combined with the knowledge of potential risk factors may contribute to perceive these goals and prevent further complications both on the mother and on the child. It is worth to note that the presence of anxiety disorder during pregnancy (Andersson et al., 2003; Robertson et al., 2004; Sutter-Dallay et al., 2004; Milgrom et al., 2008) and particularly in the 3rd trimester has been associated with a high risk (RR 9.5) of post-partum depression (Oppo et al., 2009).

Some methodological aspects limit the generalization of our results.

The first main limitation of this investigation is the small size of the overall sample of patients with PD and the utterly small size of the subgroups showing depressive comorbidity. This cannot allow us to make any firm conclusion, however it might represent an interesting observation that should be verified in larger samples.

Second, a psychiatrist did not diagnose PD, MD or md and therefore our data might be poorly reliable. However, the anxious and depressive episodes were diagnosed using the PRIME-MD, an interview performed to evaluate mental disorders in primary care, which showed a good reliability between diagnoses obtained by trained physicians and those obtained by psychiatrist (Spitzer et al., 1994). Moreover, the PRIME-MD, although not validated in pregnant populations, as stated before, showed good specificity and sensitivity in detecting both PD and MD in primary care (Spitzer et al., 1994).

\section{Conflicts of interest}

On behalf of, and having obtained permission from all the authors, I declare that no authors received funding for the research and had financial involvement that could represent potential conflicts of interest.

\section{Role of funding source}

On behalf of, and having obtained permission from all the authors, I declare that no authors received funding for the research.

\section{Acknowledgments}

We would like to thank, besides all the women involved, all the Gynecologists and Obstetricians of the Centres for Prenatal Care of the Public Health Service, District of Mantova and Reggio Emilia, for their patient collaboration and kind assertiveness that made this study possible.

\section{References}

Alonso, J. Angermeyer, M.C. Bernert, S., Bruffaerts, R., Brugha, T.S., Bryson, $\mathrm{H}$, ESEMeD/MHEDEA 2000 Investigators, 2004. Prevalence of mental disorders in Europe: results from the European Study of the Epidemiology of Mental Disorders (ESEMeD) project. Acta Psychiatr. Scand. 420, 21-27.

American Psychiatric Association, 1994. Diagnostic and Statistical Manual of Mental Disorders, Revised 4th ed. American Psychiatric Press, Washington (DC).

Andersson, L., Sundstrom-Poromaa, I., Bixo, M., Wulff, M., Bondestam, K., Åström, M., 2003. Point prevalence of psychiatric disorders during the second trimester of pregnancy: a population-based study. Am. J. Obstet. Gynecol. 189, 148-154.

Andersson, L., Sundström-Poromaa, I., Wulff, M., Åström, M., Bixo, M., 2006. Depression and anxiety during pregnancy and six months postpartum: a follow-up study. Acta Obstet. Gynecol. Scand. 85, 937-944.

Ballenger, J.C., Davidson, J.R., Lecrubier, Y., Nutt, D.J., Baldwin, D.S., den Boer, J.A., Kasper, S., Shear, M.K., 1998. Consensus statement on panic disorder from the International Consensus Group on Depression and Anxiety. J. Clin. Psychiatry $59,47-54$ 
Buist, A., Gotman, N., Yonkers, K.A., 2011. Generalized anxiety disorder: course and risk factors in pregnancy. J. Affect. Disord. 131, 277-283.

Dietz, P.M., Williams, S.B., Callaghan, W.M., Bachman, D.J., Withlock, E.P., Hornbrook, M.C., 2007. Clinically identified maternal depression before, during and after pregnancies ending in live births. Am. J. Psychiatry 164, 1515-1520.

Figueiredo, B., Conde, A., 2011. Anxiety and depression symptoms in women and men from early pregnancy to 3-months postpartum: parity differences and effects. J. Affect. Disord. 132, 146-157.

Goodman, J.H., Tyer-Viola, L., 2010. Detection, treatment, and referral of perinatal depression and anxiety by obstetrical providers. J. Womens Health 19, 477-490.

Guler, O., Sahin, F.K., Emul, H.M., Ozbulut, O., Gecici, O., Uguz, F., Gezginc, K., Zeytinci, I.E., Karatayli, S., Askin, R., 2008. The prevalence of panic disorder in pregnant women during the third trimester of pregnancy. Compr. Psychiatry 49, $154-158$

Kaufman, J., Charney, D., 2000. Comorbidity of mood and anxiety disorders. Depress. Anxiety 12, 69-76.

Kessler, R.C., McGonagle, K.A., Zhao, S., Nelson, C.B., Hughes, M., Eshleman, S. Wittchen, H.U., Kendler, K.S., 1994. Lifetime and 12-month prevalence of DSMIII-R psychiatric disorders in the United States: results from the National Comorbidity Survey. Arch. Gen. Psychiatry 51, 8-19.

Lancaster, C.A., Gold, K.J., Flynn, H.A., Yoo, H., Marcus, S.M., Davis, M.M., 2010. Risk factors for depressive symptoms during pregnancy: a systematic review. Am. J. Obstet. Gynecol. 202, 5-14.

Marchesi, C., Bertoni, S., Maggini, C., 2009. Major and minor depression in pregnancy. Obstet. Gynecol. 113, 1292-1298.

Milgrom, J., Gemmill, A.W., Bilszta, J.L., Hayes, B., Barnett, B., Brooks, Ericksen, J., Ellwood, D., Buist, A., 2008. Antenatal risk factors for postnatal depression: a large prospective study. J. Affect. Disord. 108, 147-157.

Oppo, A., Mauri, M., Ramacciotti, D., Camilleri, V., Banti, S., Borri, C., Rambelli, C., Montagnani, M.S., Cortopassi, S., Bettini, A., Ricciardulli, S., Montaresi, S., Rucci,
P., Beck, C.T., Cassano, G.B., 2009. Risk factors for postpartum depression: the role of the Postpartum Depression Predictors Inventory-Revised (PDPI-R). Results from the Perinatal Depression-Research \& Screening Unit (PNDReScU) study. Arch. Womens Ment. Health 12, 239-249.

Regier, D.A., Narrow, W.E., Rae, D.S., 1990. The epidemiology of anxiety disorders: the Epidemiologic Catchment Area (ECA) experience. J. Psychiatr. Res. 24, 3-14.

Robertson, E., Grace, S., Wallington, T., Stewart, D.E., 2004. Antenatal risk factors for postpartum depression: a synthesis of recent literature. Gen. Hosp. Psychiatry 26, 289-295.

Ross, L.E., McLean, L.M., 2006. Anxiety disorders during pregnancy and the postpartum period: a systematic review. J. Clin. Psychiatry 67, 1285-1298.

Smith, M.V., Rosenheck, R.A., Cavaleri, M.A., Howell, H.B., Poschman, K., Yonkers, K. A., 2004. Screening for and detection of depression, panic disorder, and PTSD in public-sector obstetric clinics. Psychiatr. Serv. 55, 407-414.

Spitzer, R.L., Williams, J.B., Kroenke, K., Linzer, M., de Gruy 3rd, F.V., Hahn, S.R. Brody, D., Johnson, J.G., 1994. Utility of a new procedure for diagnosing menta disorders in primary care: the PRIME-MD 1000 study. J. Am. Med. Assoc. 272, 1749-1756.

Sutter-Dallay, A.L., Giaconne-Marcesche, V., Glatigny-Dallay, E., Verdoux, H., 2004 Women with anxiety disorders during pregnancy are at increased risk of intense postnatal depressive symptoms: a prospective survey of the MATQUID cohort. Eur. Psychiatry 19, 459-463.

Wenzel, A., Gorman, L.L., O'Hara, M.W., Stuart, S., 2001. The occurrence of panic and obsessive compulsive symptoms in women with postpartum dysphoria: a prospective study. Arch. Women Ment. Health 4, 5-12.

Yonkers, K.A., Zlotnick, C., Allsworth, J., Warshaw, M., Shea, T., Keller, M.B., 1998. Is the course of panic disorder the same in women and men? Am. J. Psychiatry 155, 596-602.

Zigmond, A.S., Snaith, R.P., 1983. The Hospital Anxiety and Depression Scale. Acta Psychiatr. Scand. 67, 361-370. 